\title{
Paul Nolte
}

\section{Ständische Ordnung im Mitteleuropa der Zwischenkriegszeit}

\author{
Zur Ideengeschichte einer sozialen Utopie
}

\section{Ständische Ordnung als Utopie?}

Ständische Ordnung als Utopie - passen diese beiden Kategorien überhaupt zusammen, oder bezeichnen sie nicht vielmehr etwas prinzipiell Unvereinbares? Wenn Stände als soziale Großgruppen, die auf spezifischem Recht, spezifischer Ehre und Lebensführung beruhen, als zentrales Strukturmerkmal der traditionalen, der agrarischen, der alteuropäischen Gesellschaft gelten können, ist dann nicht die Berufung auf sic im Zeitalter der Industrialisierung, erst recht der fortgeschrittenen Moderne des 20. Jahrhunderts, pure Vergangenheitsbeschwörung und Nostalgie? Und ist damit nicht gerade das Gegenteil der "Utopie" gemeint, eines Begriffes, in dem die radikalisierte Projektion einer Zukunft, einer geradezu chiliastisch übersteigerten Moderne eine zentrale Rolle spielt? Gegen eine solche klare Unterscheidung steht aber nicht nur ein häufig sehr enger Zusammenhang von Vergangenheitssehnsüchten und Zukunftsvorstellungen, von Nostalgie und Utopie, sondern vor allem der Befund, daß die Brisanz der ständischen Ordnungsvorstellungen in den 20er und 30er Jahren häufig gerade auf ihrer spezifischen Modernität - oder dem, was die Zeitgenossen dafür hielten - beruhte. Ständische Gesellschaftskonzepte wurden an die Realitäten der arbeitsteiligen industriellen Gesellschaft und der technisierten Moderne anzupassen versucht, und eben dies, nicht einfach ihr nostalgisch-romantischer Charakter, ließ diese Ideen in der Zwischenkriegszeit ungemein attraktiv erscheinen. Dahinter stand die während dieser Zeit im deutschsprachigen Mitteleuropa weithin geteilte Überzeugung, eine ständische Sozial-, Wirtschafts- und möglicherweise auch Staatsverfassung werde die überkommene und überlebte Klassengesellschaft des 19. Jahrhunderts mitsamt dem Individualismus und politischen Liberalismus in Zukunft ablösen können und zum eigentlichen, zeitgemäßen Ausdruck einer funktional hochgradig differenzierten Gesellschaft werden.

Bei dieser "Modernität" eines eigentlich schon überlebt geglaubten Modells handelte es sich zweifellos zu großen Teilen um einen "reactionary modernism“ 


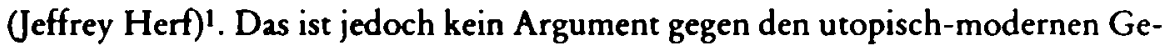
halt ständischer Gesellschafts- und Staatskonzepte, sondern unterstreicht ihre Ambiguität ebenso, wie es auf ihren weiteren soziokulturellen Kontext in der Zeit der "klassischen Moderne" des beginnenden 20. Jahrhunderts verweist, als die Grenzen zwischen radikaler Moderne und reaktionärem Atavismus auf vielen Feldern von Politik und Gesellschaft, Kultur und Wissenschaft nur noch schwer zu ziehen waren. Deshalb soll im folgenden jene Sichtweise, die in ständischen Mentalitäten oder Verfassungsmodellen ausschließlich das traditionelle und "rückwärtsgewandte" Element sieht - letztlich ein Relikt aus vorindustrieller Zeit, das noch nicht vollständig überwunden war -, in mancher Hinsicht differenziert und anders nuanciert werden.

Auf solche ständischen "Relikte" in der kulturellen Selbstdefinition und auch dem politisch artikulierten Selbstverständnis sozialer Gruppen in Deutschland zwischen dem späten Kaiserreich und der Weimarer Republik hat die sozialgeschichtliche Forschung seit langem immer wieder hingewiesen. Dabei standen verschiedene Formationen der Mittelschichten und des Bürgertums im Vordergrund, zumal die technischen und kaufmännischen Angestellten als Teil des sog. "neuen Mittelstandes“, deren weithin ständisches Selbstbewußtsein ihrem Status als de facto-Lohnabhängige keineswegs entsprochen habe ${ }^{2}$. In jüngerer Zeit ist auch darauf hingewiesen worden, wie sehr die Vorstellung einer ständischen Gliederung der Gesellschaft die politische Sprache der Weimarer Republik, zum Beispiel in den Parteiauseinandersetzungen und Wahlkämpfen, bestimmt habe ${ }^{3}$.

Eine weit verbreitete ständische Sozialmentalität und politische Semantik in diesem Sinne, wie wir sie z.B. aus den Forschungen über die Angestellten kennen, muß man freilich von expliziten Entwürfen, Modellen und Theorien ständischer Gesellschaftsordnung und ihrer Institutionalisierung im politisch-staatlichen Raum unterscheiden. Bei solchen stärker explizierten und intellektuell elaborierten Konzepten kann man dann wiederum ein weites Spektrum erkennen, das von Ideen ständischer Sozialgliederung über verschiedene $Z$ wischenstufen der ständischen Interessenformierung und -organisation bis hin zu einer regelrechten ständestaatlichen Verfassung führen konnte.

Dieser Aspekt der expliziten Reflexion ständischer Ordnung soll im folgenden im Vordergrund stehen. Er erschließt keineswegs völliges Neuland und ist im einzelnen - für verschiedene Autoren oder politisch-soziale Strömungen - schon häufiger untersucht worden. Aber im ganzen ist der deurschsprachige Ständediskurs der Zwischenkriegszeit noch nicht genügend gewürdigt worden; es fehlt eine größere Untersuchung im Zusammenhang und eine Einordnung, welche die teils

1 Vgl. Jeffrey Herf, Reactionary Modernism: Technology, Culture, and Politics in Weimar and the Third Reich (Cambridge 1984).

2 Vgl. nur Jürgen Kocka, Die Angestellten in der deutschen Geschichte 1850-1980. Vom Privatbeamten zum angestellten Arbeitnehmer (Göttingen 1981).

${ }^{3}$ Vgl. Thomas Childers, The Social Language of Politics: The Sociology of Political Discourse in the Weimar Republic, in: American Historical Review 95 (1990) 331-358. 
sehr unterschiedlichen Ansätze ständischen Denkens erfaßt und vergleicht und sie insgesamt in den Kontext von Gesellschaft und Kultur, Politik und Staatsrecht zwischen Erstem Weltkrieg und den europäischen Faschismen einordnet. In dieser Feststellung verbirgt sich bereits eine weitere These der folgenden Ausführungen: Trotz gemeinsamer Kernbestände und häufig wiederkehrender Grundelemente war Ständeidee nicht gleich Ständeidee; der Begriff konnte in mehrfacher Hinsicht ein ganz weites Spektrum abdecken, gewissermaßen in unterschiedliche Visionen von Staat und Gesellschaft „eingebaut " werden - und nicht zuletzt das machte ihn für die damaligen Zeitgenossen attraktiv.

Vorstellungen und Zukunftsentwürfe ständischer Ordnung waren in der Zwischenkriegszeit in Mitteleuropa nicht auf einen kleinen, rechtsradikalen, reaktionären oder faschistischen "lunatic fringe" beschränkt, sondern waren ganz weit verbreitet bis in den politischen "mainstream" der Weimarer Republik und die sie tragenden politischen Parteien und gesellschaftlichen Bewegungen hinein wie namentlich die sozialistische Arbeiterbewegung und den politischen Katholizismus. Sie standen im Zusammenhang der von ganz rechts bis ganz links sehr weit verbreiteten Überzeugung, die bürgerliche Welt des 19. Jahrhunderts, soweit sie durch den Weltkrieg nicht ohnehin schon zerfallen war, würde in der näheren oder ferneren Zukunft einer neuen sozialen und politischen Zukunft Platz machen. Aus der ${ }_{n} \mathrm{Krise}$ " sollte eine ${ }_{n}$ neue Ordnung " entstehen - dieser Nexus von Krisenbewußtsein und emphatischem, auch dezisionistischem Zukunftsentwurf war ja für die Z wischenkriegszeit überhaupt sehr charakteristisch ${ }^{4}$ und ist in letzter Zeit von der historischen Forschung wieder vermehrt betont worden.

Was die gesellschaftliche Ordnung im engeren Sinne, aber auch die Verfassung von Wirtschaft und Staat betraf, so wurde diese "neue Ordnung " ganz wesentlich als eine funktionalisierte berufsständische Ordnung gesehen. Überlegungen zu einer künftigen ständischen Gliederung konnten sich dann zum Beispiel auch mit hochaktuellen amerikanischen Ideen der "Industrieführung" verbinden, die nach dem Weltkrieg in Deutschland diskutiert wurden. Gegen eine solche "Synthese von Amerikanismus, ständischer Romantik und Führerkult ${ }^{\alpha}$ polemisierte zum Beispiel Ernst Troeltsch schon 1921 in seinen "Spektator"-Artikeln ${ }^{5}$. Die Tatsache, daß ständische Ideen in den 20er und frühen 30er Jahren so weit verbreitet waren und vielfach für ein modernes, in die Zukunft weisendes Konzept gehalten

4 Zum "Dezisionismus" der Zwischenkriegszeit vgl. Christian Graf v. Krockow, Die Entscheidung. Eine Untersuchung über Ernst Jünger, Carl Schmitt, Martin Heidegger (Göttingen 1958, Frankfurt a. M. 21990). Siehe auch Kurt Sontheimer, Antidemokratisches Denken in der Weimarer Republik (München 21978) 259-263; im folgenden zitiert: Sontheimer, Antidemokratisches Denken.

${ }^{5}$ Emst Troeltsch, Die Amerikanisierung Deutschlands (12. 12. 1921), in: ders., Die Fehlgeburt einer Republik. Spektator in Berlin 1918 bis 1922 (Frankfurt a.M. 1994) 237-245, hier: 244 f.; vgl. dazu z. B.: Mary P. Nolan, Visions of Modernity: American Business and the Modernization of Germany (New York 1994); als Fallstudie: Heidrun Homburg, Rationalisierung und Industriearbeit. Arbeitsmarkt - Management - Arbeiterschaft im Siemens-Konzern Berlin 1900-1939 (Berlin 1991). 
wurden, bedeutet also nicht, daß es damals nicht schon scharfsichtige Kritiker gegeben hätte, die sehr prinzipielle Einwände, besonders aus der Perspektive westlich-demokratischen Denkens, geltend gemacht hätten. Aber man sollte dennoch versuchen, den spezifischen Modernitätsidealen und dem Zukunftsglauben der Zwischenkriegszeit erst einmal auf die Spur zu kommen, um seine zeitgenössische Plausibilität zu rekonstruieren.

Um das zu run, werde ich im folgenden zunächst den Wandel des Ständebegriffes vor allem in der deutschsprachigen Sozialwissenschaft des beginnenden 20. Jahrhunderts knapp skizzieren. Auf dieser Grundlage schlage ich dann Schneisen in drei verschiedene, konkrete "Diskurszusammenhänge " der 20er und frühen 30er Jahre: Es geht zuerst um ständische Ideen in der katholischen Soziallehre; zweitens um die Debatte über den Artikel 165 der Weimarer Verfassung im Spannungsfeld $\mathrm{zwischen}$ Arbeiterbewegung und konservativer Staatslehre; drittens um ständisches Denken im Vor- und Umfeld des Nationalsozialismus. Dabei sollte das weite Spektrum und die Besonderheit der jeweiligen ständischen Vorstellungen hervortreten, aber auch Gemeinsamkeit und Grundkonsens in Voraussetzungen, Begriffen oder Organisationsmodellen deutlich werden. Abschließend frage ich noch kurz nach dem Ende ständischer Utopien in Deutschland in der Mitte des 20. Jahrhunderts.

\section{Der Wandel des Ständebegriffs: Beruf und funktionales Expertentum}

Wie war es möglich, daß ein Begriff und soziales Ordnungskonzept in der dynamisierten, hochindustriellen und massendemokratischen Gesellschaft des frühen 20. Jahrhunderts noch einmal eine solche Karriere machte, der offensichtlich dem Kontext der vorindustriellen, der agrarischen, der rechtlich gebundenen, der personalisierten Gesellschaft entstammte, deren Überwindung durch die moderne Klassengesellschaft ein Hauptthema der Geschichte des zu Ende gegangenen 19. Jahrhunderts gewesen war? Hier ist nicht der Ort, in ausführliche Überlegungen zur Begriffsgeschichte von "Stand" vor etwa 1900 einzutreten ${ }^{6}$. Die auch danach sich fortsetzende Karriere des Begriffes gewinnt jedoch vor dem Hintergrund jenes "Leidens an der Modernisierung " größere Plausibilität, das in letzter Zeit von der Sozial- und Kulturgeschichte als zentrale Erfahrung der vorletzten Jahrhundertwende genauer erforscht worden ist. Dabei spannt sich ein weiter Bogen von der Agrarromantik zur intellektuellen und akademischen Kulturkritik, von Reform- und Avantgardebewegungen bis zu einer "nervösen " Mentalität, und fast immer stößt man dabei auf ein kompliziertes Mischungsverhältnis von

6 Vgl. v.a. Wemer Conze u. a., Art. Stand, Klasse, in: Geschichtliche Grundbegriffe. Lexikon zur politisch-sozialen Sprache in Deutschland, hrsg. v. dems., Otto Brunner, Reinhart Koselleck, Bd. 6 (Stuttgart 1990) 155-284. 
Vergangenheitsbeschwörung und Zukunftssehnsucht, von Abgestoßensein und Fasziniertsein durch die kulturelle Moderne?.

Die in den ersten Jahrzehnten des 20. Jahrhunderts rasch sich vermehrenden technischen Innovationen - man denke nur an den Bereich Verkehr und Transport, mit Automobilen, Flugzeugen, Untergrundbahnen usw. - radikalisierten diesen $Z$ wiespalt in vieler Hinsicht noch. Sie versprachen eine grundlegende Transformation von gesellschaftlichen Funktionsprinzipien und alltäglichen Lebensweisen in erreichbarer Zukunft, aber sie verstärkten auch Verunsicherung und das Bedürfnis nach Ordnung und Stabilität. Deshalb ist es wohl unstreitig, und wird durch zahlreiche Beiträge auch in diesem Band sehr differenziert hervorgehoben, daß es einen engen Zusammenhang zwischen den Erfahrungen des Modernitätsschocks um 1900 und dem für das späte 19. und frühe 20. Jahrhundert so charakteristischen Utopismus gegeben hat. Ob man auf radikale Entwürfe in der Architektur oder auf die bildenden Künste, auf proletarisch-sozialistische oder auf bürgerliche Vorstellungen blickt: Nostalgie und Utopie, die Rückversicherung in einer vermeintlich besseren Vergangenheit und die radikale Fortschreibung in die Zukunft, konnten zu dieser Zeit, in Westcuropa und Nordamerika wie in Osteuropa, enge Verbindungen miteinander eingehen ${ }^{8}$.

Das gilt auch für die Ständeproblematik, deren $W_{1}$ ederaufleben im politischen und sozialwissenschaftlichen Diskurs am Beginn des 20. Jahrhunderts dieses nostalgische Element keineswegs abgesprochen werden kann. Die vermeintlich bessere Vergangenheit der (alt-)ständischen Welt vor der Industrialisierung klang meist auch dann mindestens unterschwellig an, wenn ständische Ordnung neu und auf eine moderne Zukunft hin entworfen wurde. Dennoch darf man nicht allein das Moment der Vergangenheitsbeschwörung sehen. Zum einen sollte man die Kontinuität ständischer Deutungen der Gesellschaft über das gesamte 19. Jahrhundert, und auch noch darüber hinaus, nicht unterschätzen: Der "language of class" war es in Deutschland nie wirklich gelungen, die "Ständesprache“, also die Beschreibung von sozialer Ordnung und sozialer Ungleichheit in ständischer Terminologie, zu verdrängen. Soziale Formationen, in welchem Sinne auch immer, sogar einschließlich der modernen, marktförmigen „Erwerbsklas-

7 Vgl. u.a.: August Nitschke u. a. (Hrsg.), Jahrhundertwende. Der Aufbruch in die Moderne 1880-1930, 2 Bde. (Reinbek 1989); Paul Nolte, 1900: Das Ende des 19. und der Beginn des 20. Jahrhunderts in sozialgeschichtlicher Perspektive, in: Geschichte in Wissenschaft und Unterricht 47 (1996) 281-300; Klaus Lichtblaw, Kulturkrise und Soziologie um die Jahrhundertwende. Zur Genealogie der Kultursoziologie in Deutschland (Frankfurt a. M. 1996); Joachim Radkau, Das Zeitalter der Nervosität. Deutschland zwischen Bismarck und Hitler (München 1998); Ute Frevert (Hrsg.), Das Neue Jahrhundert. Europäische Zeitdiagnosen und Zukunftsentwürfe um 1900 (Göttingen 2000); Klaus Bergmann, Agrarromantik und Großstadtfeindschaft (Meisenheim 1970); sowie Detlef J. K. Peukert, Die Weimarer Republik. Krisenjahre der klassischen Moderne (Frankfurt a.M. 1987).

8 Vgl. allg.: Lucian Hölscher, Die Entdeckung der Zukunft (Frankfurt a.M. 1999); auch ders., Weltgericht oder Revolution. Protestantische und sozialistische Zukunftsvorstellungen im deutschen Kaiserreich (Stuttgart 1989). 
sen“ (Max Weber), als "Stände" zu bezeichnen, blieb außerhalb des Diskurses der Arbeiterbewegung geläufig und selbstverständlich, nicht nur in der Alltagssprache, sondern auch in Politik und $\mathrm{W}_{\text {issenschaft }}{ }^{9}$. Zum anderen wissen wir aus der Begriffsgeschichte, daß die politisch-sozialen Leitbegriffe offen sind für grundlegende Umprägungen und Neudeutungen, und diese Geschichte semantischer Neuaufladungen ist keineswegs auf die klassische "Sattelzeit" beschränkt gewesen, sondern setzte sich ins 20 . Jahrhundert hinein fort ${ }^{10}$. Auf diese Weise sind auch die Kategorien des Standes und der ständischen Gesellschaft im ersten Drittel des 20. Jahrhunderts neu gefaßt und an die gesellschaftliche Realität der Gegenwart angepaßt worden. Kurz und überspitzt gesagt, wurde dabei aus einer sozialen Kategorie der "Geburt" und der "Ehre" eine solche des Berufes und des funktionalen Expertentums.

Dieser Wandel vollzog sich in vielen Etappen und Schattierungen, die hier höchstens angedeutet werden können - und auch das ohne jeden Anspruch auf Vollständigkeit. Innerhalb der Sozialwissenschaft, auf die ich mich im folgenden zunächst konzentrieren will, war die Zurückdrängung und Umdeutung der historischen Soziologie Max Webers dabei von erheblicher Bedeutung. Ohne die Debatte über systematische versus historische Zugangsweise in "Wirtschaft und Gesellschaft" (und überhaupt in der Weberschen Soziologie) hier aufrollen zu können, kann man doch sagen, daß Webers Begriffe des Standes und des Ständischen primär von einer historischen Zuordnung zu agrarischen Gesellschaften mit traditionalen Formen politischer Herrschaft her gedacht waren. Diese historische Korrelation schimmert jedenfalls auch dann immer sehr deutlich durch, wenn Weber sich um eine systematische Begriffsfassung bemühte und dabei die Definition im Sinne einer epochalen Abfolge "vom Stand zur Klasse" sorgfältig zu vermeiden suchte. Stände waren für ihn zudem gerade keine ökonomisch bedingten Formationen, sondern Herrschaftsstände oder (bzw. damit verknüpft) Stände einer spezifischen Ehre und Lebensführung, sei es in traditionalen Gesellschaften, sei es in seiner eigenen Gegenwart des frühen 20. Jahrhunderts ${ }^{11}$.

9 Vgl. dazu insgesamt: Paul Nolte, Die Ordnung der deutschen Gesellschaft. Selbstentwurf und Selbstbeschreibung im 20. Jahrhundert (München 2000) bes. 26, 37 ff., 159 ff.; im folgenden zitiert: Nolte, Ordnung.

$10 \mathrm{Vgl}$. Paul Nolte, Gesellschaftstheorie und Gesellschaftsgeschichte. Umrisse einer Ideengeschichte der modernen Gesellschaft, in: Thomas Mergel, Thomas Welskopp (Hrsg.), Geschichte zwischen Kultur und Gesellschaft. Beiträge zur Theoriedebatte (München 1997) 275-298.

11 Vgl. Max Weber, Wirtschaft und Gesellschaft. Grundriß der verstehenden Soziologie (Tübingen ${ }^{5} 1980$ ) bes. 177-180, 531-540. Eine klare historische Abfolge "vormoderner" Stände und "moderner" Klassen findet sich bei Weber jedoch kaum - das haben vielmehr erst Teile der Weberianischen Soziologie und Sozialgeschichte in ihn hineingelesen. Für Weber entstehen Stände "primär" durch eine "eigene ständische Lebensführung", darunter insbesondere die "Art des Berufs ${ }^{\alpha}$ (Ebd. 180, Hervorhebung im Orig.); und er bezog sich immer wieder auf Prozesse der Formierung von Ständen in der Moderne und seiner eigenen Gegenwart, z. B. in den Vereinigten Staaten von Amerika (Ebd. 535). Vgl. auch Wolfgang Schluchter, Die Entwicklung des okzidentalen Rationalismus. Eine Analyse von Max Webers Gesellschafts- 
Dieser Sichtweise Webers aber wurde in den 20er Jahren überwiegend nicht mehr gefolgt. Eine Ausnahme bildet interessanterweise Hans Freyer, der in seiner rechtshegelianisch inspirierten historischen Soziologie der bürgerlichen Gesellschaft Weber in gewisser Hinsicht sogar noch radikalisierte: Das Strukturprinzip der "Ständegesellschaft" gehörte für ihn einer bestimmten Phase der Geschichte an, es war nicht in ein allgemeines, überhistorisches Prinzip umzudeuten. So wandte sich Freyer 1931 in seiner "Einleitung in die Soziologie" gegen die "formale Soziologie“ einerseits, die eben dies betrieb, gegen „alle Romantiker der Vergangenheit und der Gegenwart" andererseits - und damit war ganz offensichtlich Othmar Spann gemeint ${ }^{12}$. Wenn man genau liest, erkennt man jedoch das Einsickern einer veränderten Terminologie, mit deren Hilfe der Ständebegriff auf Gegenwartsdiagnose und Zukunftsaufgaben hin geöffnet werden konnte. So knüpfte Freyer mit dem Hinweis auf "ständische Ethik" und „besondere Lebensform ${ }^{\text {“ }}$ einerseits an Webers Definition an, schränkte aber ein, das allein genüge noch nicht: „Nur wenn ernsthafte Aufgaben vorliegen, die bestimmte Kräfte wachzurufen und einen bestimmten Menschentypus zu züchten vermögen, gibt es Stände von geschichtlichem Rang. ${ }^{13}$ Damit verwandelte sich die historische Deskription unversehens in eine nicht mehr nur wissenschaftliche Aufgabe für die Zukunft. Dem entsprach, daß Hans Freyer in der Ständegesellschaft eine Gliederung nicht nur nach Vorrechten, sondern auch nach "Leistungen" sah" ${ }^{14}$ - mit dem Leistungsbegriff nahm er eine, wie wir noch sehen werden, schlechthin zentrale Kategorie des neuen, "modernisierten“ Ständebegriffes auf.

Die teils auf Georg Simmel zurückgehende, in den 20er Jahren ihren kurzlebigen Siegeszug antretende "formale Soziologie (in der Weimarer Republik vor allem durch Alfred Vierkandt repräsentiert) verstärkte die Neigung, soziale Begriffe wie Stand und Klasse zu enthistorisieren und als allgemeingültige Formen der Vergesellschaftung zu betrachten, die auch in der Gegenwart ihre Bedeutung nicht verloren hatten. In diese Richtung bewegte sich z.B. auch Ferdinand Tönnies in den 20er Jahren. Er unterschied, wie das meistens getan wurde, Geburtsstände von Berufsständen und sah die Existenz von Berufsständen im Deutschen Reich als ein ganz offensichtliches Faktum an, das in den Berufs- und "Standes"Organisationen der Rechtsanwälte und Ärzte, in den Handels-, Handwerks- und Gewerbekammern, in den Berufsgenossenschaften der Arbeiter usw. auch insti-

geschichte (Tübingen 1979) 120f. („Berufslage“ mit den zwei Varianten "Erwerbsklassen“ und "Berufsstände" als spezifisches Merkmal "funktionaler " sozialer Schichtung im modernen Anstaltsstaat).

12 Hans Freyer, Einleitung in die Soziologie (Leipzig 1931) 137-140, hier: 137; im folgenden zitiert: Freyer, Einleitung in die Soziologie. Vgl. hierzu und zum folgenden außerdem ders., Soziologie als Wirklichkeitswissenschaft. Logische Grundlegung des Systems der Soziologie, (Leipzig 1930) bes. 264-275 (hier ist die rein ,historische ${ }^{\alpha}$ Perspektive auf Stände und Ständegesellschaft noch klarer durchgeführt als ein Jahr später in der "Einleitung in die Soziologie ${ }^{u}$.

${ }^{13}$ Freyer, Einleitung in die Soziologie 138.

14 Ebd. 
tutionell zu Tage trete ${ }^{15}$. Im Kontrast zu Freyer erkennt man hier übrigens, daß politische und wissenschaftliche Optionen keineswegs parallel gehen mußten; Freyer blieb auch als ,konservativer Revolutionär" in vieler Hinsicht Weberianer, während Tönnies' für unsere Begriffe diffuse und antiquierte Ständetheorie mit zunehmenden Sympathien für die Sozialdemokratie einherging.

Tönnies' Sichtweise war andererseits aber gar nicht so antiquiert, weil er dem "Beruf" als sozialer Kategorie der modernen, arbeitsteiligen Gesellschaft einen hohen Stellenwert einräumte und von hier aus den Ständebegriff auf neue Weise füllte. Man kann gar nicht genug unterstreichen - und es wäre eine eigene Untersuchung wert -, welche Bedeutung der "Beruf" als Leitkategorie in der Selbstwahrnehmung der deutschen Gesellschaft am Beginn des 20. Jahrhunderts gewann. Eine weit verbreitete Sichtweise der Zeitgenossen kann man so zusammenfassen: Das 19. Jahrhundert war die Zeit der beginnenden industriellen Klassengesellschaft mit ihrer einfachen Zweiteilung in Bürgertum und Proletariat. In der weiter entwickelten Industriegesellschaft setzte sich jedoch eine hochgradige Spezialisierung und Arbeitsteilung immer mehr durch, so daß der konkrete Beruf, nicht mehr einfach der Status z. B. als Lohnarbeiter, das eigentliche Kriterium für Selbsteinschätzung und Gruppenzugehörigkeit des Einzelnen war. Dabei konnte man auch an ältere Überlegungen Gustav Schmollers zur "Arbeitsteilung" anschließen, welche die Bedeutung der Berufsarbeit für die soziale Gruppenbildung gerade auch in den unteren Schichten, in der Arbeiterschaft, besonders hervorgehoben hatten ${ }^{16}$.

Dieses Bild korrespondierte mit der schon erwähnten Überzeugung, die Klassengesellschaft des 19. Jahrhunderts gehe ihrem unaufhaltsamen Ende entgegen und verschwinde zugunsten einer neuen Moderne des funktionalen Expertentums. In seiner berühmten Untersuchung über die nUmschichtung des Proletariats" aus dem Jahre 1929 sah sogar ein aufgeklärter Marxist wie Emil Lederer dies als "die entscheidende Frage der sozialen Entwicklung in unserer nächsten $\mathrm{Zu}$ kunft: Kann sich in diesen Tendenzen zur immer stärkeren Aufgliederung und Zerspaltung der modernen Gesellschaft zugleich eine Integration zu Klassen durchsetzen? Ist der Berufsgedanke, ist die konkrete Funktion, die Aufgabe im Wirtschaftskörper das schlechthin Entscheidende für die Gruppierung, die $\mathrm{Ge}$ staltung des Bewußtseins? Sind also die Gruppierungen nach Berufen und Berufsfunktionen, hierarchisch geordnet, die letzten Formungsprinzipien der modernen

15 Ferdinand Tönnies, Art. Stände und Klassen, in: Alfred Vierkandt (Hrsg.), Handwörterbuch der Soziologie (Studienausgabe Stuttgart 1931) 188-209, hier bes. 195; im folgenden zitiert: Vierkandt, Handwörterbuch der Soziologie.

$16 \mathrm{Vgl}$. v.a. Gustav Schmoller, Das Wesen der Arbeitsteilung und der socialen Klassenbildung, in: Schmollers Jahrbuch 14 (1890) 45-105, hier: 89: „In allen mittleren und unteren Schichten ist es noch mehr die Berufsarbeit als der Besitz, welche klassenbildend wirkt.... Die Arbeiter sind weder ganz besitzlos, noch fühlen sie sich wegen ihres Nichtbesitzes als eine einheitliche Klasse; gerade die Berufsverschiedenheiten gliedern sie zu allermeist in verschiedene Gruppen. “ Zur Sozialgeschichte der Klassenbildung in Deutschland um die Jahrhundertwende vgl. z.B. Gerhard A. Ritter, Klaus Tenfelde, Arbeiter im Deutschen Kaiserreich 1871-1914 (Bonn 1991). 


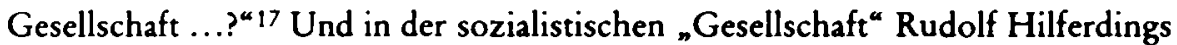
konnte man schon einige Jahre früher lesen, das Problem des Berufs sei ein Problem, das erst und spezifisch „der modernen Gesellschaft gegeben“ sei, „die sich nach der Zersetzung der ständischen Gesellschaft durch die Entstehung der freien Wirtschaft bildete ${ }^{\prime 18}$. Trat hier der Beruf noch in einen Gegensatz zur (geburts-) ständischen Ordnung, war es in den 20er Jahren bereits typischer, diese beiden Begriffe im neuen Entwurf einer funktionsmäßig gegliederten berufsständischen Gesellschaft, zu der auch eine entsprechende politische Interessenartikulation gehörte, zusammenzuziehen. Auf diesen Nexus von Beruf als spezifisch modernem System sachlich-funktionaler Differenzierung und ständischer Vision gesellschaftlicher Gesamtordnung trifft man im deutschsprachigen Mitteleuropa in den $20 \mathrm{er}$ und frühen $30 \mathrm{er}$ Jahren in ganz unterschiedlichen Kontexten, wie wir noch sehen werden.

Mit Absicht ist diese sozialwissenschaftliche Entwicklungslinie hier einmal in den Vordergrund gerückt, und der Wiener Soziologe Othmar Spann (1878-1950), der in diesem Zusammenhang häufig an erster Stelle genannt wird, bisher nur am Rande erwähnt worden. Spanns soziologisch-philosophischer "Universalismus", den er seit der Veröffentlichung des „Kurzgefassten Systems der Gesellschaftslehre" im Jahre 1914 in immer neuen Anläufen vertiefte ${ }^{19}$, ging von einem romantischen Gesellschaftsbild aus, das Adam Müller viel verdankte, und gab von hier aus den "Ständen", einschließlich einer ständestaatlichen politischen Ordnung, einen besonders prominenten Platz. Spanns Einfluß war in Österreich größer als in Deutschland - man mag sagen: seine Ständekonzeption war einer noch stärker agrarisch geprägten Gesellschaft angemessener als dem hochindustriellen, großstädtischen Deutschland. Aber es gibt auch Gemeinsamkeiten eines "modernistischen" Vokabulars, zum Beispiel in Spanns offenem Bekenntnis zum italienischen Faschismus: Mit der Überwindung von Demokratie und des Liberalismus sei, so Spann, die "Sachsouveränität ${ }^{\alpha}$ an die Stelle der "Volkssouveränität ${ }^{4}$ getreten $^{20}$. In

17 Emil Lederer, Die Umschichtung des Proletariats (1929), in: ders., Kapitalismus, Klassenstruktur und Probleme der Demokratie in Deutschland 1910-1940, hrsg. v. Jürgen Kocka (Göttingen 1979) 172-185, hier: $181 \mathrm{f}$.

is Anna Siemssen, Beruf und Erziehung, in: Die Gesellschaft 1 (1/1924) 579-584, hier: 579. Vgl. auch Werner Sombart, Beruf und Besitz, in: Archiv für soziale Gesetzgebung und Statistik 18 (1903) 1-20; ders., Art. Beruf, in: Vierkandt, Handwörterbuch der Soziologie 25-31. 19 Otbmar Spann, Kurzgefasstes System der Gesellschaftslehre (Leipzig 1914); später erweitert unter dem Titel „Gesellschaftslehre" (z. B. Leipzig ${ }^{3}$ 1930); siehe auch ders., Das Verhältnis von Ganzem und Teil in der Gesellschaftslehre, in: (Wiener) Zeitschrift für Volkswirtschaft und Sozialpolitik 1 (1921) 477-492. Zu Spann vgl. u.a. Klaus-Jörg Siegfried, Universalismus und Faschismus (Wien 1974); Martin Schneller, Zwischen Romantik und Faschismus. Der Beitrag Othmar Spanns zum Konservativismus in der Weimarer Republik (Stuttgart 1971); Reinbold Knoll, Die Sozialwissenschaften in den 20er Jahren - Österreichs Größe im Untergang, in: Knut Wolfgang Nörr u.a. (Hrsg.), Geisteswissenschaften zwischen Kaiserreich und Republik (Stuttgart 1994) 243-265.

20 Othmar Spann, Die Bedeutung des ständischen Gedankens für die Gegenwart, in: Ständisches Leben 3 (1933) 353-361, hier: 357 (Vortrag am 9. Juni 1933 vor der „Confederazione Nazionale Fascista del Commercio " in Rom). 
jedem Fall aber konnte sich in den 20er Jahren auch eine Vision wie die Spanns, die wesentlich mehr als andere Ständetheorien romantischen Idealen einer traditionalen Gesellschaft verhaftet blieb, behaupten, weil ihre Exzentrizität in der selbstverständlichen Präsenz des Ständediskurses in der "Mitte“ von Politik und Gesellschaft gar nicht weiter auffiel.

\section{Die ständische Ordnung der Zukunft - Elemente einer Utopie? Drei Skizzen}

Wenn man die Entwürfe einer ständischen Zukunft mit ihren teilweise utopisch übersteigerten Elementen genauer verstehen will, muß man zwischen unterschiedlichen politisch-sozialen Kontexten und den durch sie konstituierten "Diskursräumen " unterscheiden. Ständische Ordnungsvorstellungen konnten für ganz unterschiedliche Interessen und Bewegungen attraktiv erscheinen, aber ihre Wirkung war in keinem Fall auf einen engeren akademisch-intellektuellen Bereich begrenzt; fast immer ging es zugleich um den Versuch einer Lösung konkreter Probleme der Verfassungsordnung oder der Sozialpolitik. Wie auf diese Weise Modelle ständischer Staats- und Gesellschaftsorganisation aus verschiedenen Richtungen immer deutlicher die Debatten der 20er und frühen 30er Jahre bestimmten, soll anhand dreier Beispiele im folgenden knapp skizziert werden. Das erste Beispiel ist die katholische Soziallehre; das zweite die Diskussion um den „Räte-Artikel“ 165 der Weimarer Verfassung; das dritte die Affinität zwischen ständischem Denken und Nationalsozialismus zwischen der Mitte der 20er und der Mitte der 30er Jahre. In jedem dieser Beispiele tritt eine spezifische Verbindung von intellektuellen Milieus und politischer Praxis, und zugleich eine Verbindung von Geschichtsdeutung und Zukunftsentwurf, von Traditionalismus und Utopie hervor. Jedes der Beispiele verweist außerdem auf Überlappungen oder Konvergenzen "linken " und "rechten" Denkens; diese breite, scheinbar überideologische Ausstrahlung erklärt zum Teil die bemerkenswerte Anziehungskraft der neu-ständischen Konzepte und ist ein Merkmal auch ganz anderer Utopien des frühen und mittleren 20. Jahrhunderts. Dennoch blieben diese ständischen Entwürfe und Utopien in Deutschland nach 1933 unrealisiert, weil andere, gegenläufige Utopien, nicht zuletzt die einer rassisch homogenen Volksgemeinschaft, in den Vordergrund traten. Aber das spricht noch nicht gegen die enorme Virulenz radikalisierter Ständekonzepte in der Z wischenkriegszeit.

\section{a) Die katholische Soziallebre}

Mit der katholischen Soziallehre sind Konzepte, Debatten und Visionen angesprochen, die von vornherein eine „europäische“, jedenfalls nationale Diskursgrenzen sprengende Dimension besaßen. Andererseits ist hinreichend bekannt, daß die politisch-sozialen Ordnungsvorstellungen im Katholizismus auch des frü- 
hen 20. Jahrhunderts von der jeweiligen nationalen politischen Kultur und Verfassung maßgeblich mitgeprägt wurden und darüber hinaus, gerade in Deutschland, Besonderheiten regionaler Milieus - z. B. des rheinischen Katholizismus - eine wichtige Rolle spielten. So kann man im Umfeld des Mönchengladbacher „Volksvereins für das katholische Deutschland “ gut verfolgen, wie Ständekonzepte in eine prinzipiell eher "linke“, fortschrittsorientierte und gewerkschaftsfreundliche Position integriert wurden, von der praktischen Politik der christlichen Gewerkschaften - z. B. bei Theodor Brauer - bis hin zur intellektuellen, sozialphilosophischen Absicherung in der vor allem jesuitisch geprägten akademischen Soziallehre. Dabei teilte man die nach dem Ersten Weltkrieg nicht zuletzt auf der liberaldemokratischen Linken, im linksbürgerlichen Lager weitverbreitete Überzeugung, die tiefe Klassenspaltung der deutschen Gesellschaft müsse nun endlich durch eine neue „Volksgemeinschaft“ überwunden werden ${ }^{21}$. Für die Gesellschaft jenseits der Dichotomie von Bürgertum und Proletariat galt jedoch nicht „öde Gleichmacherei“, so der Jesuit Constantin Noppel 1921, sondern ein Zusammenwirken der verschiedenen "Stände", wobei der "Eingliederung des vierten Standes", wie es in sozialkatholischer Diktion immer noch hieß, besondere Aufmerksamkeit galt ${ }^{22}$. Das Betriebsrätegesetz von 1920 setzte dieses Ziel nin der wirtschaftlichen Urzelle, dem Einzelbetrieb“ um, doch es bedurfte darüber hinaus einer ständischen Organisation im großen Maßstab. „Das Streben nach der Volksgemeinschaft führt daher sofort, so paradox dies auch scheinen könnte “ - höchst aufschlußreich, wie Noppel selber hier die mögliche Spannung zweier Prinzipien konstatierte! - „zur Erneuerung des berufsständischen Gedankens. ${ }^{\text {23 }}$ Auch dafür bot die Weimarer Verfassung mit dem Art. 165 und dem (vorläufigen) Reichswirtschaftsrat einen begrüßenswerten institutionellen Ansatzpunkt ${ }^{24}$, auf den gleich ausführlicher zurückgekommen wird.

Dabei konnten auch innerhalb des sozialen Katholizismus mit „Ständen“ bzw. „Berufsständen“ teils sehr unterschiedliche Konzepte angesprochen sein. Während Noppel, wie wir gesehen haben, eher einen konventionellen, aus dem 19. Jahrhundert übernommenen Begriff weitertrug, lehnte sich August Pieper, der in den 20er Jahren mit zahlreichen Veröffentlichungen zu dieser Thematik im Verlag des Volksvereins hervortrat, enger an die neuromantische Ständekonzeption Othmar Spanns und dessen „Universalismus“ an, einschließlich eines spezifischen Antikapitalismus, der für die pragmatischeren Richtungen nicht unbedingt typisch war. Aber auch hier war ständische Ordnung ein Projekt für die Zukunft,

21 Vgl. Constantin Noppel J., Neuproletarier?, in: Stimmen der Zeit 100 (1921) 26-37.

22 Vgl. ebd. 29; auch August Pieper, Von der Arbeiterbewegung zum Arbeiterstande (Mönchengladbach 1920). Im folgenden zitiert: Pieper, Arbeiterbewegung.

23 Constantin Noppel J., Volksgemeinschaf, in: Stimmen der Zeit 100 (1921) 343-354, hier: 347; im folgenden zitiert: Noppel, Volksgemeinschaft. Vgl. auch ders., Dreigliederung des sozialen Organismus?, in: Stimmen der Zeit 98 (1920) 150-153.

24 Vgl. Noppel, Volksgemeinschaft z.B. 347f.; August Pieper, Berufsgedanke und Berufsstand im Wirtschaftsleben (Mönchengladbach 1925) 19; im folgenden zitiert: Pieper, Berufsgedanke. Siehe auch schon ders., Arbeiterbewegung. 
für die Gesellschaft nach dem nunmehr vermeintlich zu Ende gehenden Individualismus ${ }^{25}$. - Die spezifisch "moderne ${ }^{*}$ Ausrichtung des Ständedenkens in der katholischen Soziallehre dagegen repräsentierte die Richtung des sog. "Solidarismus", die sehr einflußreich von Gustav Gundlach (1892-1963), seit Beginn der 30er Jahre auch von Oswald v. Nell-Breuning (1890-1991), formuliert worden ist. Der Artikel Gundlachs über "Stand, Ständewesen “ in der fünften Auflage des „Staats-Lexikons“ der Görres-Gesellschaft kann dafür repräsentativ herangezogen werden ${ }^{26}$. Stand ist für Gundlach genuin „Berufsstand “ im Sinne moderner Funktionsdifferenzierung der Gesellschaft; der Geburtsstand ist nur noch eine Reminiszenz, denn „das Wesentlichste des Standesbegriffs, nämlich die gleiche gesellschaftlich bedeutsame Funktion", tritt im Geburtsstand hinter andere Kriterien deutlich zurück ${ }^{27}$.

Den modernen Berufsstand dagegen verortet Gundlach im semantischen Dreieck von "Sachgebieten", "Funktionen " und "Leistungseinheiten". Die Gesellschaft baut auf "Sachgebieten" wie "Wissenschaft ${ }^{*}$, "Kunst ${ }^{*}$, "W " $_{\text {irtschaft }}$ " auf heute würde man mit Luhmann von den Funktionsbereichen einer funktional differenzierten Gesellschaft sprechen -, ,in deren gemeinsamer Erstrebung durch Funktions- oder Berufseinheiten die einzelnen Gruppen zum umfassenden Leistungszusammenhang der ,Gesellschaft' dauernd einen “28. Stände erscheinen hier also als berufliche Expertengruppen, die spezifische Funktionen und Leistungen für das Ganze einer arbeitsteilig komplexen Gesellschaft erbringen. Das ist mehr und konkreter als eine Utopie, aber es ist interessant zu beobachten, wie Gundlach gegen Schluß seines Artikels sprachlich ins Futur wechselt und von den kulturellen und zivilisatorischen Chancen einer zukünftigen ständischen Gesellschaft spricht, die sich an das auch von ihm vorhergesehene Ende des liberalen Zeitalters anschließen wird ${ }^{29}$. Die Bestimmung von Ständen als "Leistungsgemeinschaften ${ }^{4}$ ist dann besonders von Nell-Breuning in den Vordergrund gerückt worden, ganz ausdrücklich auch noch nach 194530; gleichzeitig sei hier nur an die Affinität des

$25 \mathrm{Vgl}$. Pieper, Berufsgedanke bes. 19; auch bei Pieper spielt übrigens die Verknüpfung von Berufsständen und "Volksgemeinschaft" eine wichtige Rolle.

26 Gustav Gundlach J., Art. Stand, Ständewesen, in: Staats-Lexikon der Görres-Gesellschaft Bd. 5 (Freiburg 51932) Sp. 45-62; im folgenden zitiert: Gundlach, Stand, Ständewesen. Vgl. auch ders., Art. Ständestaat, in: Ebd. Sp. 67-71; im folgenden zitiert: Gundlach, Ständestaat. Ders., Stand und Klasse, in: Stimmen der Zeit 117 (1929) 284-293. Vgl. auch schon ders., Zur Soziologie der katholischen Ideenwelt und des Jesuitenordens (Diss. Berlin 1927) (bei Werner Sombart); sowie: Franz Schürbolz, Entwicklungstendenzen im deutschen Wirtschaftsleben zu berufsständischer Organisation (Mönchengladbach 1922). Siehe darüber hinaus: Gustav Gundlach J., Die Ordnung der menschlichen Gesellschaft Bd. 2 (Köln 1964) bes. 237-335.

${ }^{27}$ Gundlach, Stand, Ständewesen Sp. 48; vgl. zur Bedeutung der Kategorie des „Berufes“ auch ders., Berufsethos, in: Stimmen der Zeit 118 (1930) 97-106.

28 Gundlach, Stand Ständewesen Sp. 55.

${ }^{29}$ Ebd. Sp. $61 \mathrm{f}$.

30 Vgl. z.B. Oswald v. Nell-Breuning, Gesellschaftsordnung (Nürnberg 1947) bes. $32 \mathrm{ff}$. Die Bedeutung der "Leistung" für das Gesellschaftsbild Hitlers hebt überpointiert hervor: 
Vokabulars von "Leistung " und "Leistungsgemeinschaft" zur Sprache des Nationalsozialismus kurz erinnert. - Auf der anderen Seite grenzte sich der Solidarismus aber vehement von den neoromantischen Ständetheorien und namentlich von Othmar Spann immer wieder ab. Gundlach nannte es nabwegig“, den Staat selber als einen "Großstand" zu sehen; der "Staat" behielt für ihn eine Stellung gegenüber der "Gesellschaft" mit ihren berufsständischen Gliederungen, der "Staatsbürger" ging im "Standesglied" nicht auf $\$ 1$. Das ließ Raum für eine wenigstens halbe Anerkennung des Parlamentarismus und für eine Abwehr des "totalen Staates"32. Andererseits muß man sehen, daß es gerade die ständische Inanspruchnahme des Staates war, die den Nationalsozialismus in den 30er Jahren zunehmend von Spann abrücken, ja dessen Lehre als Gefahr für die staatliche Überformung des einheitlichen "Volkes" sehen ließ.

Die Auseinandersetzung über die ständische Gesellschaft in den verschiedenen Richtungen des Katholizismus, nicht nur in Deutschland, erhielt 1931 mit der Enz.yklika "Quadragesimo Anno " Pius' XI. einen neuen Schub. Sie erschien weithin als ein definitives Zeichen, daß der berufsständische Gedanke „die Zukunft für sich (hat)", wie Nell-Breuning es 1932 ausdrückte ${ }^{33}$. Aber was mit der in „Quadragesimo Anno" apostrophierten "berufsständischen Ordnung" konkret gemeint sein sollte, vor allem im Hinblick auf eine praktische Umsetzung als ständische Staatsverfassung, war in der ersten Hälfte der 30er Jahre umstritrener denn je. Hier gingen Deutschland und Österreich unterschiedliche Wege. Während die Auslegung der Enzyklika in Deutschland intellektuell vom Solidarismus dominiert blieb und politisch vom Volksverein für das katholische Deutschland ebenso wie von den christlichen Gewerkschaften - zum Beispiel auf Tagungen in Mönchengladbach und in Essen im Jahre 1932 - verfochten wurde, blieb in Österreich der romantisch-organische Universalismus Spanns viel stärker im Vordergrund, und politisch war es die "Christlich-Soziale Partei", welche die berufsständische Ordnung auf ihre Fahne schrieb und auch verfassungspolitisch umzusetzen versuchte ${ }^{34}$. Das mündete 1933/34 in den Staatsstreich von Dollfuß und die Etablierung des österreichischen Ständestaates ${ }^{35}$ - eine Option, die im Deutschen Reich

Rainer Zitelmann, Hitler. Selbstverständnis eines Revolutionärs (Hamburg 1987). Zur Kategorie der Leistung in der nationalsozialistischen Arbeitsordnung vgl. z. B. Tilla Siegel, Leistung und Lohn in der nationalsozialistischen „Ordnung der Arbeit" (Opladen 1998).

31 Gundlach, Ständestaat Sp. $67 \mathrm{f}$.

32 Vgl. ebd. Sp. 67,71 (gegen Carl Schmitt; zu diesem siehe den folgenden Abschnitt).

33 Oswald v. Nell-Breuning, Um den berufständischen Gedanken. Zur Enzyklika „Quadragesimo anno " vom 15. Mai 1931, in: Stimmen der Zeit 122 (1932) 36-52, hier: 38; im folgenden zitiert: $v$. Nell-Breuning, Um den berufständischen Gedanken. Ders., Die soziale Enzyklika. Erläuterungen zum Weltrundschreiben Papst Pius XI. über die gesellschaftliche Ordnung (Köln 21932).

${ }^{34} \mathrm{Vgl}$. dazu im deutsch-österreichischen Vergleich: Heinrich Bußhoff, Berufsständisches Gedankengut zu Beginn der 30er Jahre in Deutschland und Österreich, in: Zeitschrift für Politik 13 (1966) 451-463.

35 Vgl. allg.: Ulrich Kluge, Der österreichische Ständestaat 1934-1938. Entstehung und Scheitern (München 1984). 
kaum denkbar gewesen wäre, nicht nur wegen der dortigen Minderheitsposition des Katholizismus, sondern vor allem wegen dessen ganz anderer Ausrichtung in intellektueller wie in politischer Hinsicht. Namentlich Oswald v. Nell-Breuning kritisierte immer wieder alle korporativistischen und, mit Blick auf Italien, faschistischen Interpretationen der Ständeidee im allgemeinen und von ${ }_{n}$ Quadragesimo Anno “ im besonderen ${ }^{36}$. Dennoch: Die „linke ${ }^{4}$, fortschritts- und moderneorientierte, von Funktion und Leistung her denkende Vision einer Ständegesellschaft im deutschen Katholizismus der 20er und frühen 30er Jahre berührte sich in mancher Hinsicht ihrerseits mit der deutschen Variante des Faschismus, auch wenn nach 1933 die Wege wieder auseinander gingen.

\section{b) Die Debatte um den Art. 165 der Weimarer Verfassung}

Die Mehrdeutigkeit ständischer Utopien in der Zwischenkriegszeit tritt im nächsten Beispiel besonders deutlich hervor: Es geht dabei um den Artikel 165 der Weimarer Reichsverfassung und die teils auffällig benachbarten Vorstellungen, die sich auf der Linken und auf der Rechten damit, eigentümlich changierend zwischen Rätesystem und Berufsständen, verknüpften. Der sogenannte „Räteartikel“ 165 sah eine Wahrnehmung der "sozialen und wirtschaftlichen Interessen " der Arbeiter und Angestellten nicht nur in Betriebsarbeiterräten, sondern in einem mehrstufigen System auch über die betriebliche Ebene hinaus vor. Mit den Vertretern der Unternehmer "und sonst beteiligter Volkskreise" sollte außerdem ein "Reichswirtschaftsrat" gebildet werden, dem vor allem ein Begutachtungs- und Initiativrecht bezüglich sozial- und wirtschaftspolitisch belangvoller Gesetzentwürfe eingeräumt war. Bekanntlich ist die Verwirklichung dieses Artikels über die Einberufung eines "Vorläufigen Reichswirtschaftsrates" nie hinausgekommen, und auch dieser trat nur zwischen 1920 und 1923 im Plenum zusammen. Aber dieses faktische Scheitern darf nicht dazu verleiten, die ideenpolitische Wirkungsgeschichte des Art. 165 zu unterschätzen. In den spröden institutionellen Bestimmungen des Artikels bündelten sich sehr zentrale Hoffnungen und Erwartungen, die sich in den 20er Jahren immer wieder an eine Neuformierung sozialer Interessen in Staat und Gesellschaft der Zukunft knüpften. Denn um diese Frage ging es hier im Kern: Wie sollten die Gruppeninteressen einer entwickelten industriellen Gesellschaft organisiert sein, welche neuen Formen konnten für die ,industrial relations" im System des "Organisierten Kapitalismus" (Rudolf Hilferding) gefunden werden, und bot der klassische Parlamentarismus des 19. Jahrhunderts dafür noch die geeigneten Institutionen? Die Ansätze zu einem Neuarrangement der industriellen Beziehungen zwischen Kriegsende und Gründung der Weimarer Republik wie die "Zentralarbeitsgemeinschaft" galten deshalb vielen Zeitgenossen als Vorboten einer zukünftigen Interessenorganisation auf berufsständischfunktionaler Basis.

36 Vgl. z. B. v. Nell-Breuning, Um den berufständischen Gedanken 39. 
Die Entstehung des Artikels 165 WRV ist vor einigen Jahren von Gerhard A. Ritter präzise rekonstruiert worden ${ }^{37}$; sie stand vor allem im Kontext politischer Ideen der sozialdemokratischen Arbeiterbewegung, also der Räteidee und überhaupt von Konzepten, die etwas später von Fritz Naphtali als „Wirtschaftsdemokratie $^{4}$ bezeichnet wurden ${ }^{38}$. Aber die Ausgangsdiagnose, aus der heraus dies entwickelt wurde, ähnelte bis hinein in semantische Details auf verblüffende Weise der Zeitdiagnose der Rechten, besonders der njungen“ Rechten der 20er Jahre:

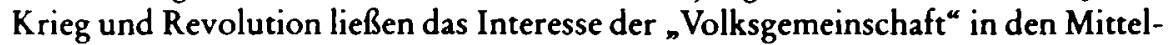
punkt rücken ${ }^{39}$, und das bedeutete auf lange Sicht eine Überwindung der bürgerlichen Demokratie. Denn "die bürgerliche Demokratie wertet", so hieß es in der entsprechenden Resolution des Berliner Rätekongresses im April 1919, „in ihrem Vertretersystem die Bevölkerung nach der bloßen Zahl. Die sozialistische Demokratie muß deren Ergänzung bringen, indem sie die Bevölkerung aufgrund ihrer Arbeitstätigkeit zu erfassen strebt. ${ }^{\text {" }} 0$ Max Cohen, der wichtigste Protagonist dieser Richtung innerhalb der SPD, scheute sogar vor der Kennzeichnung einer solchen Vertretung als „berufsständisch" nicht zurück. Mit den von ihm anvisierten "Kammern der Arbeit" werde "ein anderer Querschnitt durch das deutsche Volk gezogen" als mit dem Reichstag, denn "die Wahl zu diesem berufsständisch zusammengesetzten Parlament erfaßt das deutsche Volk in ganz anderen Schichtungen $^{\text {" }}{ }^{41}$. Tatsächlich erhielt Cohen viel ausdrückliche Zustimmung von der politischen Rechten, die in einem solchen Rätekonzept eine Annäherung der SPD an die Bismarckschen Überlegungen zu einem "Volkswirtschaftsrat" in den 1870er und 1880 er Jahren erkannten ${ }^{42}$. Doch das focht Cohen nicht an. Es sei wahr, daß berufsständische Vertretungen ,im früheren liberalen Staat" des 19. Jahrhunderts noft einen rückständigen Charakter gezeigt " hätten. „Das beweist indes gar nichts für die Gegenwart. Der alte liberale Staat ... existiert nicht mehr. ${ }^{43}$

Diese Formulierung, die genausogut von Hans Freyer, Hans Zehrer oder Carl Schmitt stammen könnte, bündelt über das Problem des Art. 165 hinaus noch einmal den Basiskonsens, die grundlegende Überzeugung aller Verfechter von

37 Gerbard A. Ritter, Die Entstehung des Räteartikels 165 der Weimarer Reichsverfassung, in: Historische Zeitschrift 258 (1994) 73-112. Siehe auch: Gerhard Schulz, Räte, Wirtschaftsstände und die Transformation des industriellen Verbandswesens am Anfang der Weimarer Republik, in: Gerhard A. Ritter (Hrsg.), Gesellschaft, Parlament und Regierung (Düsseldorf 1974) 355-366.

38 Vgl. Fritz Naphtali, Wirtschaftsdemokratie. Ihr Wesen, Weg und Ziel (Berlin 1928).

39 So Max Cohen, Deutscher Neuaufbau und Arbeiterschaft, in: Neue Rundschau 30 (1919) 656-671, hier: 657; im folgenden zitiert: Coben, Neuaufbau.

40 Ebd. 664. Vgl. auch ders., Was wird aus dem Rätegedanken?, in: Neue Rundschau 31 (1920) 657-670. Vgl. dazu neben Ritter v.a. Heinrich August Winkler, Von der Revolution zur Stabilisierung. Arbeiter und Arbeiterbewegung in der Weimarer Republik 1918-1924 (Berlin 1985) 201-205, 235-238; im folgenden zitiert: Winkler, Revolution. Auch: Nolte, Ordnung 171-174.

41 Cohen, Neuaufbau 663.

42 Vgl. dazu Winkler, Revolution $202 \mathrm{f}$.

43 Cohen, Neuaufbau 668. 
ständischen Zukunftsvisionen in den 20er und frühen 30er Jahren. Nun soll nicht verschwiegen werden, daß die Position Cohens und seiner Anhänger innerhalb der SPD bei weitem nicht mehrheitsfähig war. Im Gegenteil, zumal die sozialdemokratischen oder der SPD nahestehenden Staatsrechtler wie Hermann Heller ${ }^{44}$ oder Hugo Sinzheimer kritisierten solche Gesellschafts- und Verfassungskonzepte immer wieder heftig. Mit Berufsständen wollte Sinzheimer nichts zu tun haben; darin sah er 1920 „eine Schranke für die volle Auswirkung des demokratischen Prinzips ${ }^{45}$. Aber gleichzeitig teilte er doch jene tief in der Geschichte des deutschen Konstitutionalismus und seines "dualistischen Prinzips ${ }^{46}$ verankerte Überzeugung, die Gesellschaft müsse sich neben dem Staat eine eigene Artikulationsmöglichkeit, eine eigene "Gesellschaftsverfassung" geben, damit ihre Kräfte "unmittelbar zur Geltung kommen" und „nicht nur durch die Staatsgesetze und Staatsverwaltung hindurch ${ }^{47}$. Man erkennt daran nicht nur sehr gut bestimmte Tiefenprägungen der deutschen Arbeiterbewegung, sondern kann auch erneut beobachten, wie Traditionsbestände des 19. Jahrhunderts in den 20er Jahren nicht einfach als Nostalgie zitiert, sondern in eine Zukunftsvision hinein transformiert wurden.

Nach den Weimarer Gründungsjahren war die Geschichte des Artikels 165 weniger, als Ritters Darstellung vielleicht glauben macht, abgeschlossen; die Argumente eines Teils der Linken wurden vielmehr weitergeführt, vor allem in der konservativen Staatsrechtslehre, die sich sehr häufig auf diesen Verfassungsartikel bezog und sich überhaupt ausführlich mit dem Problem berufsständischer Interessenvertretung und Verfassung beschäftigte. Ohne die Unterschiede zwischen rechten Berufsständen und linkem Rätedenken zu verwischen, kann man doch sagen, daß die auffällige Affinität weder zufällig war noch auf einem Mißverständnis beruhte. Staatsrechtler wie Edgar Tatarin-Tarnheyden knüpften bei den Plädoyers für eine berufsständische Verfassung ihrerseits an den Berliner Rätekongreß und

44 Vgl. z.B. Hermann Heller, Rechtsstaat oder Diktatur?, in: Neue Rundschau 40 (1929) 721-735, bes. 730 ff., mit einer Polemik gegen (berufs-)ständische Konzepte, namentlich gegen Oswald Spengler.

45 Hugo Sinzbeimer, Rätebewegung und Gesellschaftsverfassung (1920), in: ders., Arbeitsrecht und Rechtssoziologie. Gesammelte Aufsätze und Reden Bd. 1 (Frankfurt a.M. 1976) 356-363, hier: 362. Vgl. auch ders., Die Grundbeziehungen zwischen Staats- und Wirtschaftsleben (1920), in: ders., Ausätze und Reden Bd. 1 bes. $368 \mathrm{ff}$.

46 $\mathrm{Vgl}$. zusammenfassend zur Kontinuität des deutschen Konstitutionalismus und seiner vordemokratischen Implikationen in die Verfassungs- und Mentalitätsgeschichte der Weimarer Republik hinein: Andreas Wirsching, Die Weimarer Republik. Politik und Gesellschaft (München 2000) bes. 49; hier findet sich weitere Literatur. Siehe auch schon Emst Fraenkel, Deutschland und die westlichen Demokratien (Stuttgart 1964) 117 ("Geburtsfehler" der Weimarer Republik).

47 Sinzheimer, Rätebewegung 357. Vgl. dagegen Leo Wittmayer, Die Weimarer Reichsverfassung (Tübingen 1922) 424 (kritisch gegenüber Sinzheimer; Wittmayer polemisierte vom Standpunkt des liberalen Parlamentarismus und Parteienstaates gegen die Affinität von Berufsständen und sozialistischen Räteideen (vgl. bes. 411 f.). Vgl. weiter: Gerhard Anschütz, Die Verfassung des Deutschen Reichs vom 11. August 1919. Ein Kommentar für Wissenschaft und Praxis (3. Bearbeitung Berlin 131930) 639-646 (Kommentar zu Art. 165)). 
die Entstehung des Artikels 165 positiv an. In seiner Marburger Antrittsvorlesung von 1922, drei Jahre später in „Schmollers Jahrbuch“ veröffentlicht, würdigte Tatarin-Tarnheyden auch die "Zentralarbeitsgemeinschaft ${ }^{\star}$ als Schritt in die richtige Richtung und kritisierte in ganz ähnlicher Diktion wie Cohen den Parlamentarismus als die „vom Westen aus gepredigte Kopfzahldemokratie ${ }^{\alpha 8}$. Zur richtigen, seiner Ansicht nach berufsständischen Interpretation des Art. 165 publizierte er noch 1930 einen ausführlichen Kommentar in monographischer Form unter dem Titel „Berufsverbände und $W_{1}$ rtschaftsdemokratie ${ }^{49}$. Wie die meisten Zeitgenossen grenzte auch Tatarin-Tarnheyden, der sich soziologisch stark von Spann beeinflussen ließ, die neuen Berufsstände scharf von den Geburtsständen der vorindustriellen Gesellschaft ab; genauso unzweifelhaft war ihm aber, daß die Berufsstände mit einer Klassengesellschaft unvereinbar waren und deren Überwindung dienen sollten 50 .

Hier ist nicht der Platz, auf diese und ähnliche Positionen - Heinrich Herrfahrdt wäre als weiterer, wichtiger Autor in der rechten Staatstheorie der 20er Jahre zu nennen ${ }^{51}$ - ausführlicher einzugehen. Nur ein markanter Endpunkt der Debatte soll noch kurz bezeichnet werden: In seinem „Hüter der Verfassung“ ging auch Carl Schmitt 1931 auf das Problem der Berufsstände, den Artikel 165 und eine eigene „Wirtschaftsverfassung “ ein. Schmitt lehnte es zwar ab, in dem Art. 165 den Keim einer Nebenverfassung der Weimarer Republik zu sehen, stimmte jedoch mit dem Blick auf die Überwindung Weimars Heinrich Herrfahrdt zu, der im „letzten Artikel der geltenden Verfassung“ zugleich den „ersten Artikel einer künftigen Verfassung “ gesehen hattes2. Für Deutschland schien Schmitt eine stände- oder rätestaatliche Verfassung freilich nicht angemessen, sie passe eher auf weithin noch agrarische Länder wie das faschistische Italien und das kornmunistische Rußland. In Deutschland konnte der Ständestaat höchstens ein Durchgangsstadium der Überwindung des liberalen Parlamentarismus auf dem Weg zum "totalen Staat “ sein. Gleichzeitig nannte er den Reichswirtschaftsrat aber auch als ein positives Beispiel für jene Form der Expertenherrschaft und des „Expertenstaates“, der durch seine Neutralität und Fachkompetenz der vermeint-

${ }^{48}$ Edgar Tatarin-Tarmbeyden, Die staatsrechtliche Entwicklung des Rätegedankens in der russischen und deutschen Revolution, in: Schmollers Jahrbuch 49 (1925) 921-937; vgl. ders., Die Berufsstände, ihre Stellung im Staatsrecht und die Deutsche Wirtschaftsverfassung (Berlin 1922); im folgenden zitiert: Tatarin-Tarmbeyden, Die Berufsstände. Siehe auch Axel Frbr. v. Freytagh-Loringhoven, Die Weimarer Verfassung in Lehre und Wirklichkeit (München 1924 ) bes. 188-191 (über "Rätegedanke und Berufsstände ${ }^{\star}$ : im Anschluß an Tatarin-Tarnheyden; rechtsnationalistische, antisemitische Position). Als klugen, kritischen Überblick vgl. Arnold Bergsträsser, Neuere Literatur zum Gedanken des berufsständischen Staates, in: Schmollers Jahrbuch 47 (1924) 283-299.

49 Edgar Tatarin-Tambeyden, Berufsverbände und Wirtschaftsdemokratie. Ein Kommentar zu Artikel 165 der Reichsverfassung (Berlin 1930).

50 Tatarin-Tarnheyden, Die Berufsstände 12-16.

51 Vgl. Heinrich Herrfabrdt, Das Problem der berufsständischen Vertretung von der französischen Revolution bis zur Gegenwart (Stuttgart 1921).

52 Carl Schmitt, Der Hüter der Verfassung (Tübingen 1931) 96-104, hier: 97 (vgl. auch Anm. 1). 
lichen Beliebigkeit des pluralistischen Parteienstaates entgegenwirken sollte. „In gewissem Sinne", so Schmith, "kann auch die ganze Institution eines aus Wirtschaftskennern und Interessenten zusammengesetzten, bei der Gesetzgebung gutachtlich mitwirkenden Reichswirtschaftsrates ... als Ansatz zu einem Expertenstaat bezeichnet werden, wenn man hier nicht sogar schon das Übergangsglied zu einer eigentlichen Wirtschaftsverfassung finden will. ${ }^{453}$ Das gibt ein weiteres Beispiel dafür, wie der Ständegedanke in Zukunftsvisionen politischer Technokratie überführt wurde.

\section{c) Ständisches Denken und Nationalsozialismus}

Aus verschiedenen Richtungen - von der Sozialwissenschaft aus, der katholischen Sozial- und Staatslehre sowie der allgemeinen Verfassungs- und Staatstheorie sind wir bereits auf Berührungspunkte zwischen ständischem Denken und Nationalsozialismus gestoßen; in der abschließenden dritten Skizze soll dieses Problem noch einmal für sich betrachtet werden: Es geht um die Genese und Umformung ständischer Gesellschafts- und Staatsvorstellungen seit der Mitte der 20er Jahre in solchen Strömungen, die unmittelbar in den Nationalsozialismus hineinführten bzw. ein Teil dieser Bewegung waren. Dabei wird man im Ergebnis dreierlei feststellen können: Erstens, Ständeideen spielten in der Genese des Nationalsozialismus eine ganz erhebliche Rolle; sie gehörten zu seinen politisch-sozialen Entwürfen und Visionen fast immer dazu. Für Hitler selber gilt das freilich kaum; und das korrespondiert mit der Beobachtung: Explizite ständische Ordnungsvorstellungen waren in intellektuellen Milieus der extremen Rechten besonders attraktiv. Zweitens: „Die" nationalsozialistische Ständekonzeption gab es gleichwohl nicht, vielmehr ein breites Spektrum unterschiedlicher und auch konkurrierender Modelle, wie das ja überhaupt für die nationalsozialistische Ideologie vor der "Machtergreifung" gilt. - Nach dem 30. Januar 1933 jedoch, drittens, traten Ideen eines "ständischen" Aufbaus des neuen, nationalsozialistischen Staates schnell in den Hintergrund, genauer: Sie wurden abgedrängt und auch bekämpft; im Gegensatz zu der Aufstiegsphase des NS galten sie jetzt nicht mehr als praktikabel und zukunftsfähig. Nach 1935 waren sie praktisch völlig verschwunden.

Aber noch einmal der Reihe nach. Eine wesentliche Wurzel nationalsozialistischen Ständedenkens kann man in den (ihrerseits vielfältigen) Strömungen der jungkonservativen Bewegung der Weimarer Republik sehen. In einer Synthese aus altem, preußisch-agrarisch-adligem, und neuem Konservatismus setzte z.B. die ${ }_{\text {"Ring }}$ "-Bewegung bereits seit Anfang der 20er Jahre auf einen ständestaatlichen Umbau als grundlegende Alternative zur Weimarer Parlamentsdemokratie. Diese Bestrebungen erhielten mit den „Blättern für ständischen Aufbau“ 1920 und ein Jahr später mit der „Vereinigung für ständischen Aufbau“ auch eine publizistische und organisatorische Basis, die jedoch nur kurz auf eigenen Füßen stehen konnte

53 Ebd. 104; vgl. über Expertenherrschaft und politische "Neutralität ${ }^{4}$ des Staates ebd. 100-115. 
und dann in der ${ }_{n}$ Ring $^{4}$-Bewegung weitergeführt wurde ${ }^{54}$. Hier griff man zwar gleichfalls den „Räteartikel“ der Reichsverfassung auf, aber der Ansatzpunkt war wesentlich weiter, auch aggressiver, als in der konservativen Staatslehre. Ständische Gliederung und autoritärer Führerstaat gehörten von vornherein zusammen; auch völkische und Rassegedanken verbanden sich damit. In sozialer Hinsicht stand wiederum die Abgrenzung gegen das Prinzip der „Klasse“ und der Klassengesellschaft im Vordergrund, gegen das die Stände als die modernere, als die zeitgemäße Form der Vergemeinschaftung hervorgehoben wurden. "Der Stand ist eine Leistungsgemeinschaft ${ }^{\text {}}$, formulierte Heinz Brauweiler, einer der führenden Autoren in diesem Umkreis, 1925. „Der Stand will leisten, die Klasse beschränkt sich darauf, Ansprüche zu erheben. "Stände waren „Leistungsgemeinschaften der Berufsarbeit" 55 .

Auf andere Weise nahmen ständische Leitvorstellungen um 1930 jedoch auch in den eher „linken“, arbeiterfreundlichen Strömungen der Konservativen Revolution und der NSDAP einen prominenten Platz ein. Das gilt z. B. für die sozialen Diagnosen des "Tat"-Kreises seit der Weltwirtschaftskrise, die immer wieder das

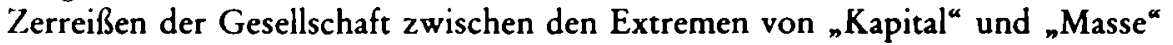
beklagten. Dagegen wollten Hans Zehrer und seine Mitstreiter eine Besinnung auf die nständische, gewerkschaftliche oder berufliche Grundlage“ stellen - man beachte den Dreiklang dieser Begriffe 56 ! Nach dem vermeintlichen Scheitern anderer Modelle hieß die Antwort auf die selbstgestellte Frage „Was bleibt?“: „Das Ständische! ${ }^{\star 57}$, und das bezog sich sowohl auf Organisierung und Selbstbewußtsein der Mittelschichten wie auf, so Ernst Wilhelm Eschmann, „die endgültige

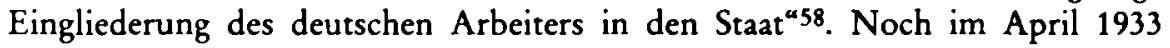
knüpfte Zehrer an die Machtergreifung die Erwartung einer Stärkung des bündisch-genossenschaftlichen, des dezentralen und eben ständischen Elementes in dem neuen Staat; ihm schwebte eine „Selbstverwaltung" vor, deren Körperschaften auf die dreifache Grundlage der konfessionellen, der landschaftlichen und der berufsständischen Zugehörigkeit gegründet sein sollten ${ }^{59}$. Die Grundlage dieser politischen Organisation sollte für Zehrer wie für so viele seiner Zeitgenossen in

$54 \mathrm{Vgl}$. Heinz Brauweiler, Berufsstand und Stand. Betrachtungen über eine neuständische Verfassung des Deutschen Staates (Berlin 1925) 7.

55 Ebd. 22, 27. Vgl. auch schon Heinz Brauweiler, Stand und Staat, in: Deutsche Rundschau 192 (1922) 168-177.

56 Anonymus, Der Zusammenbruch der bürgerlichen Parteien, in: Die Tat 22 (1930/31) 401-433, hier: 414. Allg. zum Tatkreis vgl. Sontheimer, Antidemokratisches Denken $273 \mathrm{ff}$;; ders., Der Tatkreis, in: Vierteljahrshefte für Zeitgeschichte 7 (1959) 229-260.

57 Anonymus, Der Zusammenbruch der bürgerlichen Parteien 420 (mit Blick auf die „Mittelschicht").

58 Emst Wilhelm Eschmann, Ständische Ordnung der Nation, in: Die Tat 25 (1933/34) 105-121, hier: 105.

59 Hans Zehrer, Die Revolution von rechts, in: Die Tat 25 (1933/34) 1-16, hier: 11 ; in diesem Zusammenhang sprach sich Zehrer auch dezidiert gegen eine Auflösung der Gewerkschaften aus, die vielmehr in den Neuaufbau der ständisch-beruflichen Selbstverwaltung einbezogen werden müßten - unmittelbar vor dem 2. Mai 1933! 
einer "qualitativ gestuften Gesellschaftsform ${ }^{\alpha}$ liegen, die nicht auf der Klassenposition beruhte, "sondern nach dem Prinzip der persönlichen und fachlichen Qualität bestimmt werden wird"60.

Ähnliche Vorstellungen gab es zu Beginn der 30er Jahre auch im engeren Umkreis der NSDAP, z. B. in den "Nationalsozialistischen Monatsheften ${ }^{\text {, }}$, in denen häufig Vertreter des "sozialistischen" Flügels der Partei zu Wort kamen. Der "richtige", also nicht marxistische Sozialismus wurde hier geradezu als eine "sinnvoll geordnete Ständegemeinschaft" definiert ${ }^{61}$. Der "Handarbeiterstand" solle auf diese Weise, so argumentierte Ludolf Haase, ${ }_{n}$ seine Eingliederung in die Volksgemeinschaft finden", und als politischen Überbau stellte er sich "eine Zusammenfassung der Stände in einem Wirtschaftsparlament" vor, das der "Selbstverwaltung" dienen und gleichzeitig die eigentliche, politische Staatsführung beraten solle ${ }^{62}$. Bernhard Köhler, der sich in der für Wirtschafts- und Sozialpolitik zuständigen Hauptabteilung IV der NSDAP-Reichsleitung auf Arbeitsbeschaffungspolitik spezialisierte ${ }^{63}$, definierte seinerseits Sozialismus als das "Recht auf Arbeit", und die Gewähr für die Sicherung dieses Rechtes liege "in der Hand der ständischen Organisation, in der die Arbeiterschaft selbst wirkt "64. Auch hier übrigens - wenn auch auf andere Weise als in der katholischen Soziallehre - waren ständische Gliederung und "Volksgemeinschaft " mühelos miteinander vereinbar.

Aber es deuteten sich wichtige Verschiebungen an, die auf eine immer stärkere Einschränkung des ständischen Prinzips hinausliefen. "Ständischer Aufbau" und berufsständische Gliederung sollten für die Neuordnung der Wirtschaft zunächst noch von Bedeutung bleiben, aber eben auch nur hier; aus den eigentlichen staatlichen Kompetenzen, so sah es 1933 auch Theodor Adrian v. Renteln, einer der "Ständeexperten“ der NSDAP aus dem Umfeld des „Kampfbundes für den gewerblichen Mittelstand“, hatten sich die Berufsstände herauszuhalten ${ }^{65}$. Max Frauendorfer, der bis 1936 dem „Amt für ständischen Aufbau“ in der Reichsleitung der Partei vorstand und besonders 1933 mit zahlreichen Veröffentlichungen zur Bedeutung des ständischen Gedankens im Nationalsozialismus hervortrat, ordnete die ständische Gliederung bereits eindeutig dem völkischen Prinzip unter und schloß zugleich aus, daß der "nationalsozialistische Staat" ein "Ständestaat"

60 Hans Zehrer, Die dritte Front, in: Die Tat 24 (1932/33) 97-120, hier: 102.

61 Ludolf Haase, Marxismus und Nationalsozialismus Die Ablösung der Zerstörung durch organischen Aufbau, in: NS-Monatshefte 1 (1930) 201-223, hier: 204.

62 Ebd. 220.

${ }^{63} \mathrm{Vgl}$. Martin Broszat, Der Staat Hitlers. Grundlegung und Entwicklung seiner inneren Verfassung (München 121989) 77; im folgenden zitiert: Boszat, Staat Hitlers.

64 Bermhard Köhler, Das Recht auf Arbeit, in: NS-Monatshefte 3 (1932) 290-305, hier: 292, 304.

65 Adrian v. Renteln, Nationalsozialistischer Wirtschaftsneubau, in: NS-Monatshefte 4 (1933) 403-406, hier: 405. Vgl. Broszat, Staat Hitlers $208 \mathrm{f}$. Siehe hierzu auch: Heinrich August Winkler, Unternehmerverbände zwischen Ständeideologie und Nationalsozialismus, in: Vierteljahrshefte für Zeitgeschichte 17 (1969) 341-371; Manfred Oblsen, „Ständischer Aufbau" und Monopole, in: Zeitschrift für Geschichtswissenschaft 22 (1974) 28-46. 
sein könne66. Auch könnten die Stände nicht in einem Verhältnis der Über- und Unterordnung zueinander stehen; nur in sich sollten sie "vertikal ${ }^{\alpha}$ gegliedert sein und im übrigen "sich völlig gleichberechtigt gegenüber" stehen. Dahinter stand wieder die prinzipielle Unterscheidung, die zwischen den alten, aristokratischen „Geburtsständen“ einerseits, den modernen „Berufsständen “ andererseits gemacht wurde, denn: „Der Nationalsozialismus vertritt das Leistungsprinzip. ${ }^{\alpha 7}$ Irgendeine Anknüpfung an den Artikel 165 der Weimarer Verfassung, der ,in einem Versuch zur Verewigung und Legalisierung des Klassenkampfes “ stecken geblieben sei, schloß Frauendorfer kategorisch aus ${ }^{68}$. Ähnlich argumentierte zeitweise auch Robert Ley, doch läßt sich bei ihm zugleich die generelle Tendenz gut ablesen, den Einflußbereich des Ständischen noch weiter zu begrenzen: Nicht nur der Staat, sondern auch die Gesellschaft sollte davon freigehalten werden, weil jede Art der Segmentierung letztlich der homogenen Volksgemeinschaft widersprach. Was übrig blieb, war der ständische Aufbau als Organisierung der Wirtschaft: „Während der ständische Aufbau die neue Wirtschaftsordnung formt“, so Ley 1933 in einer Rede vor den „Gaufachberatern für Ständischen Aufbau“ in Bernau, ,formt die Arbeitsfront die neue Gesellschaftsordnung, die heute noch in Schichten und Klassen auseinander strebt ${ }^{\text {"69. }}$.

Damit ist fast schon der Endpunkt dieser Entwicklung in der Mitte der 30er Jahre bezeichnet: Der "Ständische Aufbau“ wurde schrittweise zu Grabe getragen, auch in seinen Staats- und Parteiorganisationen; zuletzt stellte im Februar 1936 das „Amt für ständischen Aufbau“ seine Tätigkeit ein, und Hitler untersagte jede weitere Diskussion über das Projekt ${ }^{70}$. Die Anhänger Othmar Spanns wurden verfolgt, nach dem „Anschluß 1938 kam es auch zu Verhaftungen. Den Ausklang der nationalsozialistischen Beschäftigung mit ständischen Zukunftsvorstellungen bildeten einige halbwissenschaftliche Rückblicke in Buchform, welche die Ständeidee jetzt zunehmend der überwundenen Vergangenheit zuordneten: „Die Ständeideologien der Systemzeit und ihre Überwindung “, lautete sehr bezeichnend der Titel eines 1941 erschienenen Buches von Justus Beyer ${ }^{71}$. Es waren vor allem zwei Gründe, aus denen ständische Ideen mit dem Nationalsozialismus nicht mehr zusammenpaßten: zum einen der Konflikt mit der Vision der „Volksgemeinschaft “, deren nationalsozialistische Variante sich, anders als ihr katholi-

66 Max Frauendorfer, Der Ständische Gedanke im Nationalsozialismus (München 1933) bes. 24; im folgenden zitiert: Frauendorfer, Der Ständische Gedanke. Vgl. auch ders., Der ständische Gedanke, in: NS-Monatshefte 4 (1933) 398-403; sowie Willy Müller, Grundzüge einer neuen Sozialpolitik, in: NS-Monatshefte 4 (1933) $409-417$.

67 Frauendorfer, Der Ständische Gedanke $23 \mathrm{f}$. Ähnlich auch: Wilhelm Rössle, Ständestaat und politischer Staat, in: Die Tat 26 (1934/35) 102-112.

68 Frauendorfer, Der Ständische Gedanke 27.

69 Robert Ley, Vom Wesen des Ständischen Aufbaus, in: NS-Monatshefte 4 (1933) 388-398.

$70 \mathrm{Vgl}$. dazu Broszat, Staat Hitlers $226 \mathrm{ff}$.

71 Justus Beyer, Die Ständeideologien der Systemzeit und ihre Überwindung (Darmstadt 1941). Vgl. dazu Sontheimer, Antidemokratisches Denken 199. Siehe auch: Walter Adolf Jöbr, Die ständische Ordnung. Geschichte, Idee und Neuaufbau (Leipzig 1937) (eine bei Werner Sombart entstandene Berliner Dissertation, die nüchterner gehalten ist). 
sches Pendant, mit Ständen nicht vertrug ${ }^{72}$; zum anderen der Konflikt mit dem "totalen Staat" und seinem unmittelbaren Durchgriff auf den Einzelnen, der nicht durch intermediäre Stände abgefangen werden durfte. Das war die neue Utopie, gegenüber der manche Utopien der $20 \mathrm{er}$ und frühen $30 \mathrm{er}$ Jahre wieder als antiquiert galten. Auch innerhalb der "reaktionären Moderne " gab es eben unterschiedliche, teils gegensätzliche Visionen und Utopien.

\section{Ausblick: Nach den Utopien}

Konnte nach dem Zusammenbruch der nationalsozialistischen Utopien in Deutschland noch einmal an die älteren ständischen Zukunftsvorstellungen angeknüpft werden? Aus zwei Gründen gewannen entsprechende Versuche in der Mitte des 20. Jahrhunderts keine durchschlagende Überzeugungskraft mehr. Erstens hatten solche Entwürfe in dem zunehmend westlich beeinflußten Sozialund Verfassungsdenken der späten 40er und 50er Jahre keinen Raum mehr, und zweitens artikulierte sich immer häufiger eine grundlegende Skepsis gegenüber jeglicher Art von Utopien, die auf eine Überwindung und ideale Neugestaltung gegenwärtiger Verhältnisse abzielten. Nicht nur in Mitteleuropa hatten sich die utopischen Energien, die sich seit der Kulturkrise der Jahrhundertwende aufgebaut hatten, verbraucht.

Aber die Vorstellung von einem ganz radikalen Bruch wäre falsch. Vielmehr gab es durchaus Kontinuitäten des ständischen Denkens in die Frühgeschichte der Bundesrepublik hinein, weil es für Teile des bürgerlich-konservativen Lagers naheliegend schien, auf „bewährte“ Modelle sozialer Gliederung und politischer Organisation zurückzugreifen, nachdem die Nationalsozialisten, wie es aus dieser Perspektive schien, jede Ordnung aufgelöst und gewaltsam zerstört hatten. In den Zukunftsvorstellungen des Widerstandes am Anfang der 40er Jahre gewannen ständische Ideen vor allem dort größere Bedeutung, wo Verbindungen zur katholischen Soziallehre bestanden; insgesamt blieb ihr Einfluß jedoch begrenzt ${ }^{73}$. Auch nach 1945 war die Kontinuität im sozialen Katholizismus weitaus am stärksten ausgeprägt. Besonders Oswald v. Nell-Breuning knüpfte zunächst - erst in den frühen 50er Jahren änderte er allmählich seine Position - nahtlos an seine um 1930 formulierten Überzeugungen an. In einem Artikel für die „Frankfurter Hefte" schlug er 1947 erneut eine Gliederung der Gesellschaft in "Leistungsgemeinschaften" auf beruflicher Grundlage als einen Weg zur Überwindung der kapitalistischen Gesellschaft vor. „In dieser leistungsgemeinschaftlichen oder, wie man sie mit einem leider sehr mißverständlichen und tatsächlich meist mißverstandenen Ausdruck zu bezeichnen pflegt, , berufsständischen' Ordnung der Ge-

72 Siehe dazu auch noch: Georg Weippert, Der Stand und sein Gefüge, in: Volksspiegel 1 (1934) 266-271.

${ }_{3}$ Vgl. z. B. Ger van Roon, Neuordnung im Widerstand. Der Kreisauer Kreis innerhalb der deutschen Widerstandsbewegung (München 1967) $52 \mathrm{ff}, 412 \mathrm{ff}$., $424 \mathrm{ff}$. u. passim. 
sellschaft würden die ,Klassen' der kapitalistischen Klassengesellschaft als Klassen nicht mehr bestehen." ${ }^{74}$ Nell-Breuning blieb dabei nicht nur den inhaltlichen Konzepten und der Semantik der frühen 30er Jahre erstaunlich treu, sondern auch der für moderne Utopien so charakteristischen radikalen, fast chiliastischen $\mathrm{Zu}$ kunftsprojektion: Die berufsständische und leistungsgemeinschaftliche Ordnung sollte sich in einer Zukunft jenseits der kapitalistischen Gesellschaft, und als prinzipielle Alternative zu ihr, verwirklichen.

Sozialkatholische, „linke“ Strömungen der CDU griffen Nell-Breunings Gedanken anfangs auf und versuchten sie zur Grundlage der Unionspolitik zu machen ${ }^{75}$, aber das spiegelte nie die Mehrheitsposition und zumal nicht die Auffassungen Konrad Adenauers und Ludwig Erhards. Vielmehr überwog schon zu Beginn der 50er Jahre eine diffusere Form der Mittelstandsideologie, die ihrerseits eine Vorgeschichte im Kaiserreich und in der Weimarer Republik hatte, die jedoch nicht Bestandteil eines utopischen Neugliederungsprojekts der ganzen Gesellschaft $\mathrm{war}^{76}$. Besonders die intellektuellen Protagonisten des Ordoliberalismus der sog. "Freiburger Schule" der Nationalökonomie, die durch Erhard einen überragenden Einfluß auf die Wirtschafts- und Gesellschaftspolitik der frühen Bundesrepublik gewannen, wandten sich in den Nachkriegsjahren immer wieder schr explizit gegen die berufsständischen Vorstellungen der katholischen Soziallehre. Walter Eucken erhob den Vorwurf, ,eine gewisse romantische Verklärung des Mittelalters" zu betreiben und erklärte Ständeprinzip und Ständestaat für unvereinbar mit einer Wettbewerbsordnung 77 . Dabei ging es wiederum nicht nur um einen Streit der Konzepte, sondern um Grundsätzlicheres: nämlich um die Überwindung dessen, was Alfred Müller-Armack als den „utopischen Ansatz “ des politischen und sozialen Denkens kritisierte ${ }^{78}$. Die sozialen Utopien von links oder rechts hatten in Unfreiheit geführt, so argumentierte Müller-Armack, und die radikale Verabsolutierung eines einzelnen Ordnungsprinzips führte in die Irre. Man mußte sich deshalb nvon solcher utopischen Verabsolutierung einzelner sozialer Ziele abwenden ${ }^{\text {" } 79}$.

${ }^{4}$ Oswald v. Nell-Breuning, Kapitalismus und Sozialismus in katholischer Sicht, in: Frankfurter Hefte 2 (1947) 665-681, hier: $668 \mathrm{f}$. Vgl. auch ders., Gesellschaftsordnung. Wesensbild und Ordnungsbild der menschlichen Gesellschaft (Nürnberg 1947) 34-48 („Leistungsgemeinschaftliche Ordnung"); ders., Berufsständische Ordnung und Monopolismus, in: Ordo 3 (1950) 211-237.

75 Vgl. z. B.: "Erbe und Aufgabe der christlichen deutschen Sozialpolitik“, in: Politisches Jahrbuch der CDU/CSU 1 (1950) 67-72, hier: 71: „Die gesellschaftliche Neuformung soll sich auf berufsständischer oder leistungsgemeinschaftlicher Grundlage vollziehen und aus der klassenkämpferischen Auseinandersetzung zur Zusammenarbeit der sozialen Gruppen untereinander führen."

76 Vgl. allg. dazu: Nolte, Ordnung 318-351.

77 Walter Eucken, Grundsätze der Wirtschaftspolitik, hrsg. v. Edith Eucken, K. Paul Hensel (Bern 1952) 148, 348. Siehe zu diesem Konflikt auch Nolte, Ordnung 290-303.

78 Alfred Müller-Armack, Die Wirtschaftsordnungen sozial gesehen, in: Ordo 1 (1948) 125154, hier: $141 \mathrm{ff}$.

79 Alfred Müller-Armack, Diagnose unserer Gegenwart. Zur Bestimmung unseres geistesgeschichtlichen Standorts (Gütersloh 1949) 250. 
